\title{
Penile shortening complaints in males with erectile dysfunction: a narrative review on penile lengthening procedures during penile prosthesis surgery
}

\author{
Mahmoud I. Khalil ${ }^{1}$, Bruno Machado ${ }^{2}$, Alexandre Miranda $^{3}$, Ehab Eltahawy ${ }^{4}$ \\ ${ }^{1}$ Department of Urology, University of Rochester Medical Center, Rochester, New York, USA; ${ }^{2}$ Department of Urology, University of Arkansas \\ for Medical Sciences, Little Rock, Arkansas, USA; ${ }^{3}$ Section of Andrology \& Reconstructive Urology, Department of Urology, Hospital Federal de \\ Ipanema, Rio de Janeiro, RJ, Brazil; ${ }^{4}$ Department of Urology, University of Michigan, Michigan, USA \\ Contributions: (I) Conception and design: MI Khalil, B Machado, E Eltahawy; (II) Administrative support: MI Khalil, E Eltahawy; (III) Provision of \\ study materials or patients: MI Khalil, B Machado, A Miranda; (IV) Collection and assembly of data: MI Khalil, A Miranda; (V) Data analysis and \\ interpretation: MI Khalil, B Machado, E Eltahawy; (VI) Manuscript writing: All authors; (VII) Final approval of manuscript: All authors. \\ Correspondence to: Ehab Eltahawy, FACS. Professor of Urology, University of Michigan, 1301 Mercy Drive, Muskegon, MI 49444-1837, USA. \\ Email: eltahawy@umich.edu.
}

\begin{abstract}
Patients complaining of short penile length pose a challenge in urology practice. Those men who present seeking penile lengthening surgery usually overestimate 'normal' penile length, and may in often cases relate their penile length with the degree of masculinity and self-esteem. Penile prosthetic devices are the gold standard treatment of erectile dysfunction (ED) after failure of conservative options. Penile shortening is the most prevalent long-term complaint after successful inflatable penile prosthesis (IPP) placement. This has a significant impact on patient's overall satisfaction and quality of life. Using PubMed, we performed a thorough literature review of the current procedures of preservation or enhancement of penile length as well as reported perioperative protocols in patients undergoing penile prosthesis (PP) insertion. Keywords used were "penile lengthening", "penile enhancement", "penile girth", "inflatable penile prosthesis" and "glans augmentation". Several surgical techniques can be offered in the setting of penile shortening concurrently with PP insertion, e.g., sub-coronal approach of PP placement, sliding technique, modified sliding technique (MoST), multiple-slide technique (MuST), and tunica mesh expansion procedure (TMEP). Adjuvant techniques can also improve subjective penile length include, ventral phalloplasty, suprapubic lipectomy, suspensory ligament release and use of expanding penile implants. Preoperative protocols including use of a vacuum erectile device, traction therapy also seem to improve postoperative outcomes, minimizing postoperative pain, and encouraging the early device use. Currently, there is no consensus among experts on a particular lengthening procedure or when they can be performed to optimize outcomes. Furthermore, it is imperative to set proper expectations before surgery, with extensive patient and partner counseling. When used in the properly selected patient, penile lengthening procedures show promising results with minimal complication rates.
\end{abstract}

Keywords: Penile lengthening; penile augmentation; inflatable penile prosthesis (IPP); penile length restoration

Submitted Nov 17, 2020. Accepted for publication Mar 23, 2021.

doi: $10.21037 /$ tau-21-27

View this article at: http://dx.doi.org/10.21037/tau-21-27 


\section{Introduction}

Erectile dysfunction (ED) is defined as the chronic inability to achieve or sustain a penile erection and is deemed one of the most common medical conditions in men (i.e., $50 \%$ of men $>70$ years) (1). Sexual health plays a substantial role not only in the individuals' quality of life but also their partners' emotional, mental and physical well-being (2). Given the close relation between psychological and physiological factors in the setting of ED, the American Urological Association (AUA) guidelines suggest referral to a mental health professional to ensure treatment adherence and reduction of performance anxiety (3). After failure of conservative treatment options of ED, penile prosthetic devices have been the gold standard treatment that include the malleable penile prosthesis (MPP), a two-piece or a three-piece inflatable penile prosthesis (IPP) (4). The IPP have been available and periodically advanced since first introduced by Scott $e t$ al. in 1973 (5).

Most men seeking penile lengthening surgery usually overestimate "normal" penile length and relate their penile length with their degree of masculinity and self-esteem (6). Patients with penile shortening complaints without ED are common at the urologist's office, and represent a challenging dilemma in the practice. In this article, we aimed to address structural and anatomical conditions that can contribute to objective penile shortening.

The penile prosthesis (PP) surgery itself is reported, as a common cause of complaint of subjective loss of penile length. Studies showed that PP insertion did not change the stretched penile length, which is shorter than the normal erect length, but the loss of glanular engorgement is appointed by some studies as the cause of the patient's complaints of subjective penile shortening, leading to emotional distress and patient's dissatisfaction $(7,8)$.

Several medical conditions that may cause actual penile shortening can also be associated with ED, e.g., Peyronie's disease (PD), recurrent priapism with corporal fibrosis, prostate cancer with its various treatment modalities such as radical prostatectomy, radiation therapy, and androgen deprivation therapy (9-11). Several literature research correlated decreased penile length and girth with higher rates of dissatisfaction, and impairment in the quality of life of the patients (12). However, PD with associated ED is the only actual scenario into which penile lengthening procedures (PLP) are currently accepted as an option of treatment (13).

In this article, we review different techniques of restoration and enhancement of penile length in the setting of PP insertion using MPP or IPP, reported in the literature. We also suggest the adoption of a new unified terminology to describe accurately the PLP goals.

We present the following article in accordance with the Narrative Review reporting checklist (available at http:// dx.doi.org/10.21037/tau-21-27).

\section{Concept of penile lengthening}

The concept of penile lengthening in the literature is confusing. It includes a myriad of procedures that actually don't increase the corpora cavernosa length. The term of penile lengthening surgery was initially used in surgeries to correct PD, where grafts were used to equalize the shortened side of corpus cavernosum with the longer one. However, these procedures in fact do not really increase the total length of corpora cavernosa but equalize the shortened side with longer one (14).

In this article, we describe the procedures available in the literature on penile lengthening and propose a new classification that distinguishes the procedures by their aim.

In our classification, the term PLP is reserved for surgeries that offer real increase in the total corpora cavernosa length. When the surgeries aim to equalize the short side of corpora cavernosa with the long side without real increasing (elongation) of the total length we classified them as penile restoration procedures (PRP). If no incision is made into the corpora cavernosa, i.e., there is no real anatomical change in the size of the corpora and offering only a cosmetic perception of increased penile length, we classified it as visual penile lengthening procedures (VPLP).

The PLP, however, can only be performed in patients that already have ED, since the damage of the penile sinusoidal architecture caused by tunical lengthening is extensive enough to hinder a physiological erection and consequently a PP implantation is mandatory. The major limitation of lengthening gain is the distensibility of neurovascular bundle (NVB), which must be dorsally dissected and separated from the corpora cavernosa during all PLP.

\section{PLP}

Several surgical techniques have been reported to enhance penile length during placement of PP. A brief comparison 
Table 1 Comparison between reported studies utilizing different techniques of penile lengthening

\begin{tabular}{|c|c|c|c|c|c|}
\hline Technique & Study & Patients, $n$ & $\begin{array}{l}\text { Average gained } \\
\text { length }(\mathrm{cm})\end{array}$ & $\begin{array}{l}\text { Follow-up } \\
\text { period (mo) }\end{array}$ & Patient satisfaction \\
\hline $\begin{array}{l}\text { Circumferential } \\
\text { grafting }\end{array}$ & $\begin{array}{l}\text { Sansalone et al. } \\
2012\end{array}$ & 23 & $2.8(2.2-4.5)$ & 22 & $\begin{array}{l}90 \% \text { were satisfied with the cosmetic and } \\
\text { functional result of surgery }\end{array}$ \\
\hline \multirow[t]{2}{*}{ Sliding technique } & Rolle et al. 2012 & 3 & 3.2 & 13 & Average IIEF score is 60 \\
\hline & Rolle et al. 2016 & 28 & 3.2 & 37 & Progressive improvement in IIEF and EDITS \\
\hline MuST & $\begin{array}{l}\text { Egydio and } \\
\text { Kuehhas } 2018\end{array}$ & 138 & $3.1(2.0-5.0)$ & 15.2 & IIEF increased from 22 to 66 points at 6 months \\
\hline TMEP & Egydio 2020 & 416 & $3.3(2.0-6.0)$ & 36 & IIEF increased from 21 to 68 points at 6 months \\
\hline
\end{tabular}

MoST, modified sliding technique; MuST, multiple-slit technique; EDITS, erectile dysfunction inventory of treatment satisfaction; IIEF, International Index of Erectile Function; TEMP, tunica mesh expansion procedure.

of these techniques with a summary of outcomes is shown in Table 1.

\section{Circumferential grafting}

In 2012, Sansalone et al. published a study on 23 patients with PD and ED with severe penile shortening. The surgical technique involves subcoronal penile degloving, elevation of the NVB and ventral urethral dissection. After induced erection is performed, a bisector line is incised circumferentially in the tunica albuginea at the area of maximum curvature (Figure 1). The $\mathrm{PP}$ is inserted, and the exposed area is covered with a graft. The authors reported a mean of $2.8-\mathrm{cm}$ gain in penile length. The complications were decreased glans sensitivity (20\%) and residual curvature $(15 \%)$. The overall patient satisfaction rate was $90 \%(15)$.

\section{Sliding technique}

In 2012, Rolle et al. first described the sliding technique in a small series to achieve penile lengthening in patients with PD associated with severe penile shortening (14). Using a subcoronal incision to deglove the penis, the NVB is dissected and raised off the entire penile shaft. Similarly, the urethra is dissected and separated from the corpora cavernosa. A couple of lateral longitudinal incisions of approximately $4-\mathrm{cm}$ length are made at 3 and 9 o'clock of the corporal bodies bilaterally. Then, a semicircular proximal incision is made dorsally and a similar distal incision is made ventrally connecting the two longitudinal incisions. Gentle traction on the glans is placed to allow for penile lengthening which will result in two rectangular defects. The longitudinal incisions are secured with absorbable sutures and the defects are covered with porcine small intestinal submucosal grafts (Figure 2). A PP was placed through the proximal incision by the standard approach and a drain was left before closure. In Rolle $e t$ al. study, no major complications or bleeding were recorded and the average increase in penile length obtained was $3.2 \mathrm{~cm}$ (14). In a larger cohort of 28 patients using both porcine small intestinal submucosa and acellular porcine dermal matrix to cover the tunical defects, one patient on anticoagulation therapy had a profuse bleeding that required blood transfusion. Another patient had PP infection that required removal of the device (16).

Wilson et al. described a series of glans necrosis following PP implantation in 21 patients. Among 7 (33\%) patients, sliding technique was utilized with extensive mobilization of urethra. The authors have anecdotally referred this to the compromise of the distal penile circulation that might be associated with the extensive dissection of the urethra and NVB. However, owing to the nature of the study and collection of data, considering sliding technique as a risk factor could not be assessed (17).

\section{Modified sliding technique (MoST)}

The MoST was described by Egydio and Kuehhas and is a modification of the sliding technique (18). Using the subcoronal incision, the usual dissection and separation of the Buck's fascia and the urethra is done. The corpora 


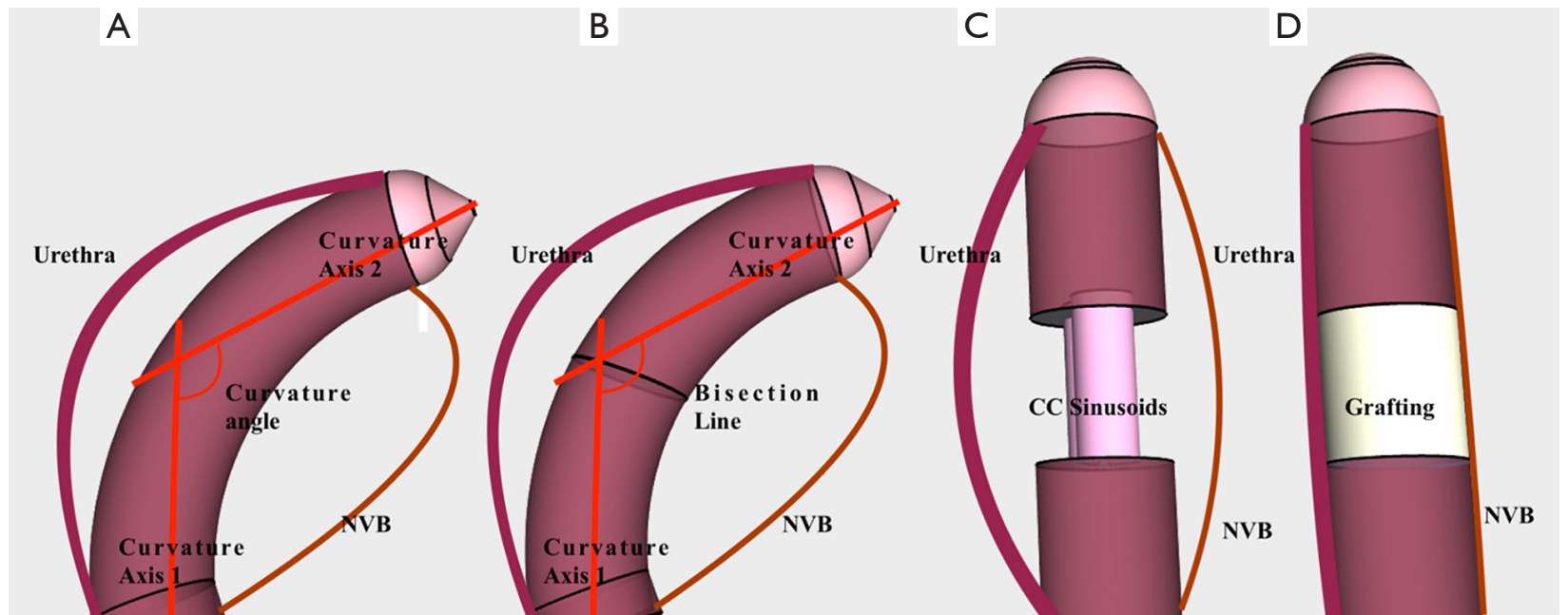

Figure 1 Circumferential grafting procedure. (A) After dissection of urethra and NVB, an artificial erection is induced and the curvature axis are marked. (B) A bisection line is traced dividing the curvature angle. (C) The penis is stretched, and the penile curvature is corrected exposing the corpus cavernosum sinusoids. (D) After the PP is implanted, the exposed area is covered with a graft and the urethra and NVB are replaced at the anatomical position. NVB, neurovascular bundle; PP, penile prosthesis.

cavernosa incisions were the same as in the sliding technique, however, the ventral semicircular incision (from 3 to 9 o'clock) was done $2 \mathrm{~cm}$ proximal to the coronal sulcus and the dorsal incision 1-2 $\mathrm{cm}$ was distal to the penoscrotal junction. PP was placed through the two separate corporotomies that were created proximal to the dorsal semilunar incision. The major modification is foregoing placement of grafts at the sites of tunical defects. The proximal defect is covered by Buck's fascia and the distal one is covered by cavernous tissue and urethra (Figure 2). Results of MoST on 143 patients with median follow-up of 9.7 months showed that the mean increase of penile length was $3.1 \mathrm{~cm}$ (range, $2-7 \mathrm{~cm}$ ) with no recorded $\mathrm{PP}$ infection (18).

\section{Multiple-slit technique (MuST)}

The MuST technique is a further variation of MoST and was introduced in 2016 (19) and modified in 2018 (20). The major difference in MuST is using multiple pairs of dorsal and ventral semicircular incisions along the penile shaft instead of a single incision on each surface. This results in multiple small tunical defects that don't need covering by grafts (Figure 2).

This technique was implemented on 138 patients (103 had MPP and 35 had IPP) with median follow-up of 15.2 months. Results demonstrated $3.1 \mathrm{~cm}$ (range, 2-5 cm) of mean penile length increase. One case of glans necrosis was reported with no PP infection (20).

\section{Expansion technique}

One of the authors (M.A.) used flexible 3D printed models to analyze different ways of tunica incision and expansion. The technique was then applied in surgical correction of PD and ED associated with penile shortening (Figure $3 A, B, C, D, E, F$ ).

\section{Tunica mesh expansion procedure (TMEP)}

TMEP is an innovative non-grafting technique that is proposed to achieve penile lengthening without the resultant large tunica defects (21). In 2018, Garaffa et al. published a video showing the use of TMEP. After penile degloving and dissection of the NVB and urethra, a threepiece IPP was then inserted though the same approach. The cylinders have been intentionally upsized of $2 \mathrm{~cm}$ from the original corporal measurements. The tunica albuginea was then expanded in girth and length by performing multiple small incisions in a mesh pattern until satisfactory curvature correction is achieved and adequate girth and length are restored. As all tunical incisions were less than $1 \mathrm{~cm}$ in length, the risk of aneurysm of the cylinders was minimal and therefore grafting of the defect was not necessary (22). In 2020, Egydio described the TMEP in his report on 
A

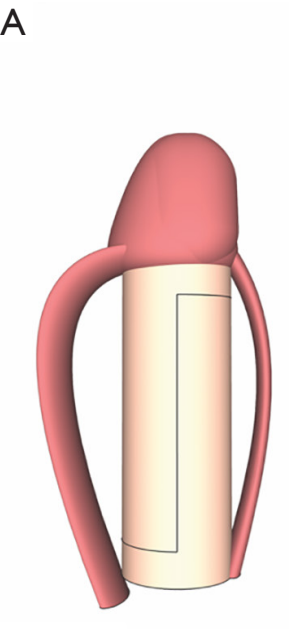

C

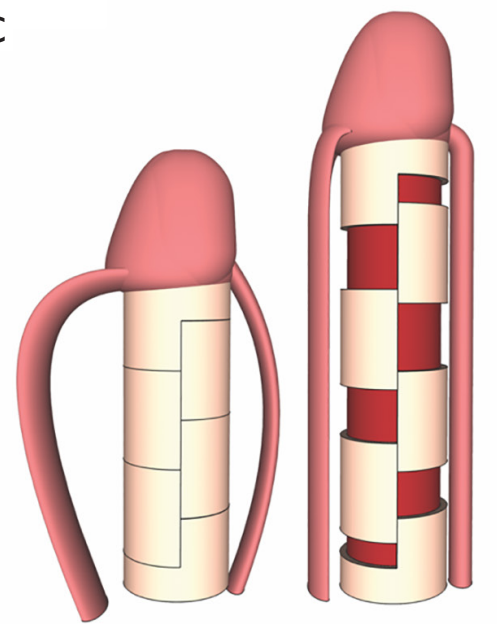

B
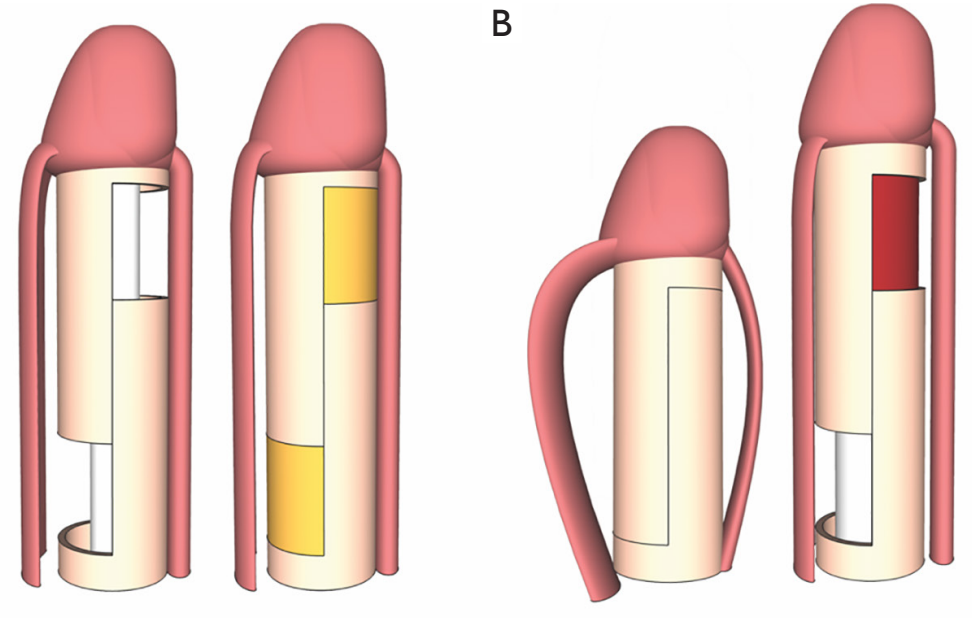

D

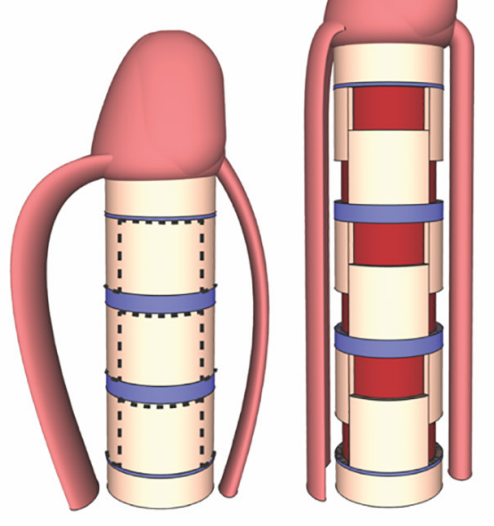

Figure 2 Penile lengthening procedures. (A) Sliding technique: two long tunica albuginea semi-circumferential defects covered by grafts (grafts in yellow); (B) modified sliding technique (MoST): two long tunica albuginea semi-circumferential defects covered with the dartos fascia (no grafts); (C) multiple sliding technique (MuST) 6 small tunica albuginea semi-circumferential defects covered with the dartos fascia; (D) expansion: Twelve non continuous small $1 / 4$ of circumference defects covered with the dartos fascia (no grafts).

416 patients (23). Unlike Garaffa, he did not perform any urethral separation as corpus spongiosum provides adequate elasticity and the main limitation is thought to be the length of the NVB.

The TMEP allows for tissue expansion and eliminates cylinder bulging and indentations while maintaining corporal strength. In Egydio report, the estimated intraoperative penile length gain was $3.3 \mathrm{~cm}$ (range, 2-6 cm). Reported complications were postoperative hematoma (20\%), temporary partial glans numbness (3.8\%), temporary anorgasmia (7\%) and PP infection in one patient (0.24\%) (23).

\section{Expanding penile implants}

Length and girth expanding penile implants have been available on the market since 1990 and they can provide 1-2 $\mathrm{cm}$ of additional length mostly in men in normal straight penises (24). AMS 700 Ultrex $^{\circledR}$ (American Medical Systems, Minnetonka, Minnesota, USA) was the most commonly used and provided up to $20 \%$ penile length expansion. However, a high rate of S-shape deformity and cylinder failure rate were reported following placement (25). The latter assumed to be caused of tearing of the bi-directional middle fabric weave of the cylinder. Subsequently, a new design was 

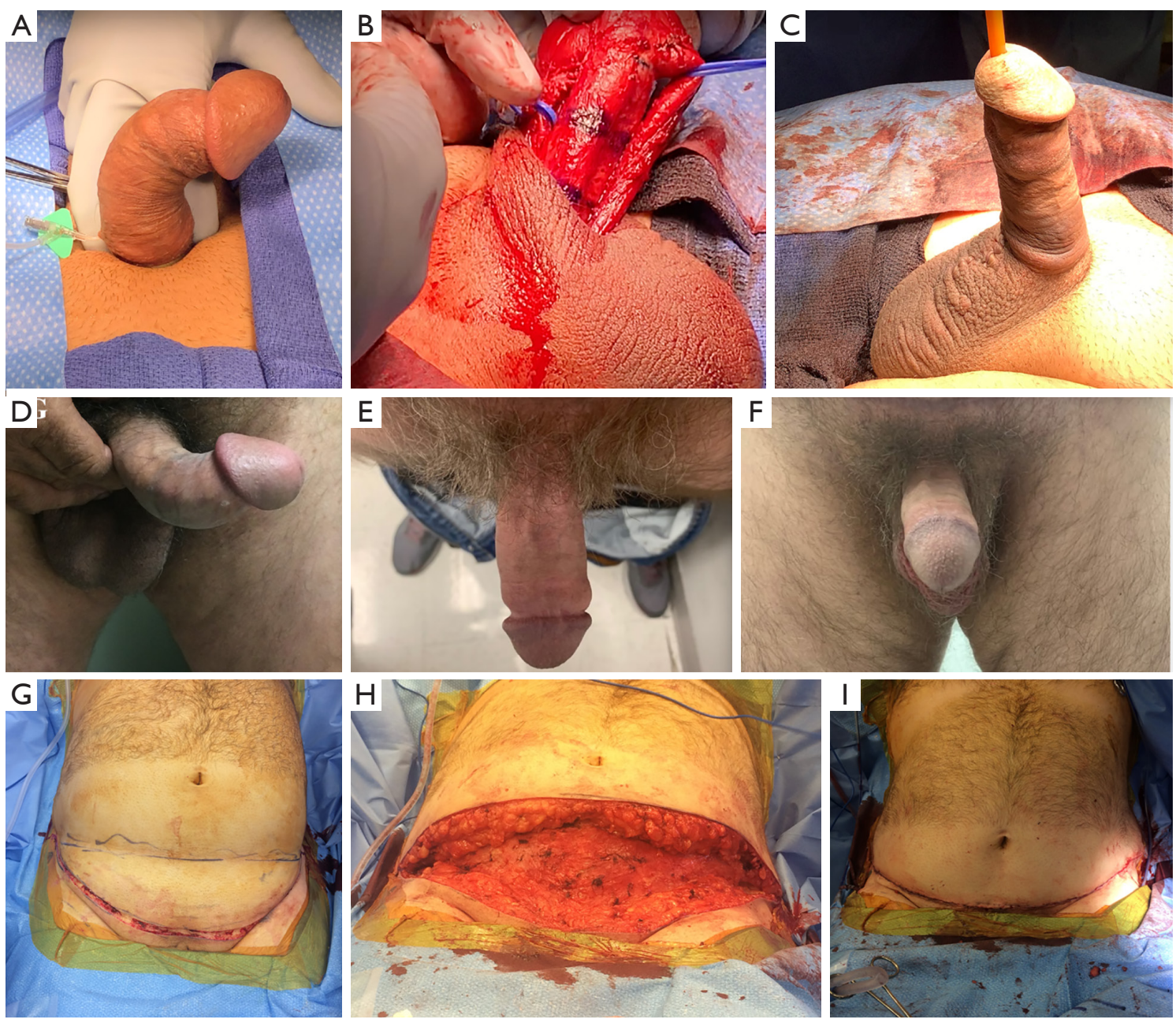

Figure 3 Case presentation. (A) Peri-operative artificial erection; (B) semi-degloved penis with the expansion technique landmarks drawn; (C) intraoperative picture after correction with the expansion technique; (D) preoperative artificial erection; (E,F) IPP implantation with expansion technique with 3-month outcome; (G,H,I) suprapubic dermolipectomy. IPP, inflatable penile prosthesis.

introduced in 1993 and showed significantly decreased rates of cylinder failure compared to the pre-modification device (26). More recent the AMS 700 LGX prosthesis seems to increase $0.6 \mathrm{~cm}$ of penile length at 6 months, due to its capacity to increase girth and length during inflation (27).

\section{VPLP}

VPLP techniques do not elongate the corpora cavernosa size, but rather provide the illusion of a more elongated penile shaft (Table 2).

\section{Ventral phalloscrotoplasty}

Ventral phalloscrotoplasty is a technique that can be utilized to provide a perceived increased length especially in cases of high insertion of the penoscrotal junction at the penile shaft. This technique can also be used simultaneously during PP placement. The incision starts from the ventral surface of the proximal penile shaft and extends to the anterior scrotum. A wedge-shaped skin segment is incised at the penoscrotal junction, and then the resulted diamondshaped defect is closed along the penile shaft using absorbable interrupted sutures (28). 
Table 2 Comparison between selected studies utilizing different techniques of visual penile lengthening procedures

\begin{tabular}{|c|c|c|c|c|c|}
\hline Technique & Study & Patients, $\mathrm{n}$ & Outcomes & $\begin{array}{l}\text { Follow-up } \\
\text { period }\end{array}$ & Complications \\
\hline $\begin{array}{l}\text { Ventral } \\
\text { phalloscrotoplasty }\end{array}$ & $\begin{array}{l}\text { Miranda-Sousa et } \\
\text { al. } 2007\end{array}$ & 43 & $\begin{array}{l}84 \% \text { of patients reported } \\
\text { subjective increased } \\
\text { length }\end{array}$ & 17 months & $\begin{array}{l}\text { wound hematoma [2/43] and focal } \\
\text { superficial wound dehiscence }[3 / 43]\end{array}$ \\
\hline Suprapubic lipectomy & $\begin{array}{l}\text { Baumgarten et al. } \\
2019\end{array}$ & 8 & $\begin{array}{l}\text { Patients reported } \\
\text { excellent cosmetic and } \\
\text { functional outcomes }\end{array}$ & 256 days & $\begin{array}{l}\text { Prosthetic infection [1/8] after } \\
\text { inadvertent early removal of drain }\end{array}$ \\
\hline $\begin{array}{l}\text { Suspensory ligament } \\
\text { release after IPP } \\
\text { insertion }\end{array}$ & Borges et al. 2006 & 303 & $\begin{array}{l}93 \% \text { reported satisfaction } \\
\text { with IPP performance and } \\
\text { penile length }\end{array}$ & $\mathrm{n} / \mathrm{a}$ & $\begin{array}{l}\text { Ejaculation difficulty (4\%), infection } \\
(2 \%) \text { and hematoma }(1.3 \%)\end{array}$ \\
\hline
\end{tabular}

IPP, inflatable penile prosthesis.

In Miranda-Sousa et al. study on 43 patients who had ventral phalloscrotoplasty concomitantly with PP placement, $98 \%$ of patients reported good satisfaction of the surgical procedure and $84 \%$ reported increased in penile length (29).

\section{Suprapubic lipectomy}

Patients with excess suprapubic fat pad because of weight gain may complain of shortened penile length which is buried underneath the suprapubic fat. Horton et al. first described the surgical technique for the buried penis, which included excision of the suprapubic fat and securing the suprapubic skin to the rectus fascia (30). Lately, Hakky et $a l$. reported a technique that included panniculectomy with suction-assisted lipectomy and anchoring of herniated pubic skin to the abdominal wall (31). Most recently, two studies; Shaeer et al. and Shah et al. described the technique of the suprapubic lipectomy that can be utilized simultaneously with PP surgery with good postoperative outcomes (Figure 3G,H,I) (32,33).

\section{Suspensory ligament release}

The suspensory ligament arises from the linea alba and provides dorsal support and stabilization of an erection by attaching midline to the penile root. Surgeries to release the suspensory ligament can be performed with either suprapubic lipectomy or with PP placement. Notably, it is usually combined with a V-Y skin plasty (34). The suspensory ligament tends to reattach after being incised, so it is important for patients to wear stretch or weight devices to prevent such event. Placement of a silicone buffer as a spacer can be utilized as well. One disadvantage of this technique is the potential ventral change in penis direction during erection. Borges et al. performed a study on 303 patients who underwent release of suspensory ligament after PP insertion, results showed that $93 \%$ of patients reported satisfaction with device performance, and penile length (35).

\section{Penile girth expansion (PGE) procedures}

Several strategies for PGE are available; however, there is an obvious lack of clinical recommendations and robust literature that adequately describe indications or strategies primarily for penile girth enlargement (36). The role of medical therapy with oral phosphodiesterase type 5 (PDE5) inhibitor in PGE has not been sufficiently studied. Whereas, vacuum devices and traction therapy didn't seem to provide increase in penile girth in the reported studies (37).

Penile injection therapy with several materials has been described. The most common of which are autologous fat injection, liquid injectable silicone, and cosmetic soft tissue filler such as hyaluronic acid, calcium hydroxylapatite, collagen, polymethyl-methacrylate microspheres (PMMA) (38-40). Generally, these types of injections offer mixed satisfaction results, with some reported serious adverse effects such fat and silicone embolism and diffuse penile fibrosis. Prospective long-term studies are warranted, thus, utilizing these products in the context of PGE should be considered off-label and approached with caution.

Dermal fat graft has been described by Spyropoulos et al. in 4 patients. Results showed mean girth gain of $2.3 \mathrm{~cm}$ at the base and $2.6 \mathrm{~cm}$ at the corona. However, there were reported complications such as paraphimosis, pain on 
erection and penile curvature because of graft sclerosis (41). Also, porcine dermal acellular matrix graft was reported on 69 patients with satisfactory results (42). Additionally, corporoplastic phalloplasty by using bilateral corporal venous grafts was described by Austoni et al. on 39 patients. Results showed average increase of erect penile diameter of $1.36 \mathrm{~cm}$ at 9 months follow-up. No obvious penile girth increase was reported in the flaccid state (43).

\section{Case presentation}

The patient presented is a 57-year-old gentleman who presented with complains of ED, PD and penile shortening. On physical exam he had a partially concealed penis due to suprapubic panniculus (SPP), and penile shortening. The flaccid penile length under maximum stretching was $9 \mathrm{~cm}$. The patient estimated a loss of $5 \mathrm{~cm}$ of his penile length.

Penile erection was induced with 40 micrograms of Alprostadil. We noticed a multiplanar curvature; dorsal and lateral to the left $\left(70^{\circ}\right.$ and $50^{\circ}$, respectively). After extensive patient education, where the expectations of size gain, risks and potential benefits were discussed, we offered him a two-stage procedure: panniculectomy (VPLP) followed by implantation of PP after 3 months using the expansion technique to give him a maximum gain in length (Figure 3).

After the dermolipectomy was performed, $1 \mathrm{~cm}$ of penis was exposed, giving to the patient the visual gain in the penile length. Three months later, the PP insertion concomitantly with PLP was performed where an additional $3 \mathrm{~cm}$ of penile length was gained. Postoperatively, the patient experienced glanular numbness for 6 weeks and was able to resume sexual activity 2 months after the second surgery. At 6-month follow-up, the patient returned to clinic reporting excellent satisfaction with the results.

\section{Discussion}

The only current indication for PLP in adults is the presence of $\mathrm{PD}$, and even in those cases, there is no consensus on the optimal procedure among the experts (42). A confounding factor in the literature is the poor definition of what is called PLP. Grafting procedures used to correct PD only equalize the short with the long side of corpora cavernosum length, e.g., $\mathrm{H}$ incision and Double Y. PLP provide a real length extension of the corpora cavernosum length such as circumferential grafting, sliding technique and TMEP. Other procedures such as suprapubic lipectomy, ventral phalloscrotoplasty and suspensory ligament release can only provide a visual illusion of penile elongation. Currently medical literature classifies all these procedures as PLP even though not all of them they do not increase the corpora cavernosa length for real.

To unify the terminology, the procedures should be named by their actual aim in increase the corpora cavernosa length as discussed earlier (Table 3). PRP refer to techniques that aim to equalize a corpora cavernosa asymmetry, like in procedures of $\mathrm{PD}$. These procedures include plaque incision or partial plaque excision and grafting at the area of maximum deformity. There are different types of grafts that can be used such as synthetic, autologous, and allografts. Graft material is sized to the resulted defect and sutured in place. These procedures are associated with a high risk of ED with reported rate of 5-54\% (44).

Since 2012, there has been an increasing number of studies addressing PLP, reflecting the evolving interest of both physicians and patients in those procedures, with trend toward less invasive interventions. The techniques moved from large corporal defects with or without graft $(14,18,20)$ to small defects using the skin graft mesh principle $(22,23)$. It seems that the future direction is for a minimally invasive solution to penile girth and length augmentation.

To date, there is no consensus among experts on a particular PLP that would lead to the optimal outcome. In the same context, wise patient selection and setting shortand long-term realistic expectations are substantial prior to electing a procedure rather than the other. Preoperative discussions and tracking of patient's previous visits and surgeries can reveal more generalized psychiatric problems such as body dysmorphic disorder, in this case, involvement of a mental health specialist would be of great value (45).

Adequate patient education on other factors that may limit the expected outcome of the lengthening procedure should be emphasized. These limitations include the NVB length and preexisted medical conditions that affect microcirculation such as diabetes mellitus and peripheral vasculopathy. Also, higher rates of infection have been reported in some series of PLP which may be referred to the extensive dissection and reconstruction performed in these techniques compared with the exclusive PP insertion. Nevertheless, advancements of surgical technique, shorter operative time, use of coated implants and no-touch technique could further decrease infection rates (46). Thus, these procedures should be performed only by surgeons with extensive experience.

This review is not without limitations. Owing to the limited number of patients in the reported studies, the 
Table 3 New classification of penile lengthening techniques according to length extension

\begin{tabular}{lll}
\hline Type & Aim & Examples \\
\hline Penile lengthening procedures (PLP) & $\begin{array}{l}\text { Increases the penile size by increasing the } \\
\text { corpora cavernosal length }\end{array}$ & $\begin{array}{l}\text { Circumferential grafting, sliding technique, MoST, } \\
\text { MuST, and tunica mesh expansion procedure }\end{array}$ \\
Visual penile lengthening procedure (VPLP) & $\begin{array}{l}\text { Increases penile size perception without } \\
\text { real increase of the corpora cavernosa size }\end{array}$ & $\begin{array}{l}\text { Ventral phalloscrotoplasty, suprapubic lipectomy, } \\
\text { and suspensory ligament release }\end{array}$ \\
Penile restoration procedures (PRP) & $\begin{array}{l}\text { Equalizes the shorter side of the penis with } \\
\text { the longer side }\end{array}$ & $\begin{array}{l}\text { Graft surgeries for PD except complete } \\
\text { circumferential grafting }\end{array}$ \\
\hline
\end{tabular}

MoST, modified sliding technique; MuST, multiple-slit technique; PD, Peyronie's disease.

retrospective nature and the fact that several studies reported subjective penile length outcomes, robust statistical analysis of the results was limited.

\section{Conclusions}

Several conditions associated with significant penile length loss and ED creates tremendous negative impact on patients' emotional and psychological wellbeing. Several PLP can be performed concurrently with PP insertion in patients with severe ED and penile shortening. Owing to the technical complexity of these surgeries, they should be performed by surgeons with adequate experience. The use of less complex procedures such as ventral phalloscrotoplasty, suprapubic lipectomy can also provide satisfactory results even when used alone. Proper patient selection, extensive education and setting realistic expectations are essential to prevent patient dissatisfaction postoperatively. Penile length enhancement can only be achieved by the longitudinal increase of the corpora cavernosa during PP implantation. These procedures were reported to improve patient satisfaction with promising results. Future research is needed to identify the role of those techniques, their typical candidates, and how much length gain the patients can safely expect from them.

\section{Acknowledgments}

Funding: None.

\section{Footnote}

Provenance and Peer Review: This article was commissioned by the Guest Editors (Francisco E. Martins and Tobias S. Köhler) for the series "Controversies and Considerations of Penile Surgery" published in Translational Andrology and
Urology. The article has undergone external peer review.

Reporting Checklist: The authors have completed the Narrative Review reporting checklist. Available at http:// dx.doi.org/10.21037/tau-21-27

Peer Review File: Available at http://dx.doi.org/10.21037/ tau-21-27

Conflicts of Interest: The authors have completed the ICMJE uniform disclosure form (available at http://dx.doi. org/10.21037/tau-21-27). The series "Controversies and Considerations of Penile Surgery" was commissioned by the editorial office without any funding or sponsorship. The authors have no other conflicts of interest to declare.

Ethical Statement: The authors are accountable for all aspects of the work in ensuring that questions related to the accuracy or integrity of any part of the work are appropriately investigated and resolved.

Open Access Statement: This is an Open Access article distributed in accordance with the Creative Commons Attribution-NonCommercial-NoDerivs 4.0 International License (CC BY-NC-ND 4.0), which permits the noncommercial replication and distribution of the article with the strict proviso that no changes or edits are made and the original work is properly cited (including links to both the formal publication through the relevant DOI and the license). See: https://creativecommons.org/licenses/by-nc-nd/4.0/.

\section{References}

1. Sánchez-Cruz JJ, Cabrera-Leon A, Martin-Morales A, et al. Male erectile dysfunction and health-related quality of life. Eur Urol 2003;44:245-53. 
2. Wassersug R, Wibowo E. Non-pharmacological and nonsurgical strategies to promote sexual recovery for men with erectile dysfunction. Transl Androl Urol 2017;6:S776-94.

3. Burnett AL, Nehra A, Breau RH, et al. Erectile Dysfunction: AUA Guideline. J Urol 2018;200:633-41.

4. Holtmann N, Edimiris P, Andree M, et al. Assessment of SARS-CoV-2 in human semen-a cohort study. Fertil Steril 2020;114:233-8.

5. Scott FB, Bradley WE, Timm GW. Management of erectile impotence. Use of implantable inflatable prosthesis. Urology 1973;2:80-2.

6. Mondaini N, Ponchietti R, Gontero P, et al. Penile length is normal in most men seeking penile lengthening procedures. Int J Impot Res 2002;14:283-6.

7. Lee KC, Brock GB. Strategies for maintaining penile size following penile implant. Transl Androl Urol 2013;2:67-73.

8. Akin-Olugbade O, Parker M, Guhring P, et al. Determinants of patient satisfaction following penile prosthesis surgery. J Sex Med 2006;3:743-8.

9. Dillon BE, Chama NB, Honig SC. Penile size and penile enlargement surgery: a review. Int J Impot Res 2008;20:519-29.

10. Haliloglu A, Baltaci S, Yaman O. Penile length changes in men treated with androgen suppression plus radiation therapy for local or locally advanced prostate cancer. J Urol 2007;177:128-30.

11. Vasconcelos JS, Figueiredo RT, Nascimento FL, et al. The natural history of penile length after radical prostatectomy: a long-term prospective study. Urology 2012;80:1293-6.

12. Smith JF, Walsh TJ, Conti SL, et al. Risk factors for emotional and relationship problems in Peyronie's disease. J Sex Med 2008;5:2179-84.

13. Nehra A, Alterowitz R, Culkin DJ, et al. Peyronie's Disease: AUA Guideline. J Urol 2015;194:745-53.

14. Rolle L, Ceruti C, Timpano M, et al. A new, innovative, lengthening surgical procedure for Peyronie's disease by penile prosthesis implantation with double dorsalventral patch graft: the "sliding technique". J Sex Med 2012;9:2389-95.

15. Sansalone S, Garaffa G, Djinovic R, et al. Simultaneous penile lengthening and penile prosthesis implantation in patients with Peyronie's disease, refractory erectile dysfunction, and severe penile shortening. J Sex Med 2012;9:316-21.

16. Rolle L, Falcone M, Ceruti C, et al. A prospective multicentric international study on the surgical outcomes and patients' satisfaction rates of the 'sliding' technique for end-stage Peyronie's disease with severe shortening of the penis and erectile dysfunction. BJU Int 2016;117:814-20.

17. Wilson SK, Mora-Estaves C, Egydio P, et al. Glans Necrosis Following Penile Prosthesis Implantation: Prevention and Treatment Suggestions. Urology 2017;107:144-8.

18. Egydio PH, Kuehhas FE. Penile lengthening and widening without grafting according to a modified 'sliding' technique. BJU Int 2015;116:965-72.

19. Gaffney CD, Pagano MJ, Weinberg AC, et al. Lengthening strategies for Peyronie's disease. Transl Androl Urol 2016;5:351-62.

20. Egydio PH, Kuehhas FE. The Multiple-Slit Technique (MUST) for Penile Length and Girth Restoration. J Sex Med 2018;15:261-9.

21. Rigaud G, Berger RE. Corrective procedures for penile shortening due to Peyronie's disease. J Urol 1995;153:368-70.

22. Garaffa G, Capece M, Chiriaco G, et al. Peyronie's Disease: Tunical String-vest Incisions for Girth and Length Restoration after Penile Prosthesis Implantation. 2018. Available online: https://www.vjpu-issm.info/videos/ peer-reviewed/1-penile-prosthesis-malleable-inflatablepenile-prosthesis-ipp/1-a-first-time-implant/1-a-elengthening-procedures/item/141-peyronie-s-diseasetunical-string-vest-incisions-for-girth-and-lengthrestoration-after-penile-prosthesis-implantation. Accessed 09/01/2020.

23. Egydio PH. An Innovative Strategy for Non-Grafting Penile Enlargement: A Novel Paradigm for Tunica Expansion Procedures. J Sex Med 2020;17:2093-103.

24. Shaeer O. Supersizing the penis following penile prosthesis implantation. J Sex Med 2010;7:2608-16.

25. Wilson SK, Cleves MA, Delk JR 2nd. Ultrex cylinders: problems with uncontrolled lengthening (the S-shaped deformity). J Urol 1996;155:135-7.

26. Milbank AJ, Montague DK, Angermeier KW, et al. Mechanical failure of the American Medical Systems Ultrex inflatable penile prosthesis: before and after 1993 structural modification. J Urol 2002;167:2502-6.

27. Negro CL, Paradiso M, Rocca A, et al. Implantation of AMS 700 LGX penile prosthesis preserves penile length without the need for penile lengthening procedures. Asian J Androl 2016;18:114-7.

28. Caso JR, Myers MD, Wiegand L, et al. Phalloplasty and penile implant surgery. Curr Urol Rep 2009;10:475-7.

29. Miranda-Sousa A, Keating M, Moreira S, et al. Concomitant ventral phalloplasty during penile implant 
surgery: a novel procedure that optimizes patient satisfaction and their perception of phallic length after penile implant surgery. J Sex Med 2007;4:1494-9.

30. Horton CE, Vorstman B, Teasley D, et al. Hidden penis release: adjunctive suprapubic lipectomy. Ann Plast Surg 1987;19:131-4.

31. Hakky TS, Suber J, Henry G, et al. Penile enhancement procedures with simultaneous penile prosthesis placement. Adv Urol 2012;2012:314612.

32. Shaeer O, Shaeer K, AbdelRahman IF. Simultaneous Suprapubic Lipectomy and Penile Prosthesis Implantation. J Sex Med 2018;15:1818-23.

33. Shah BB, Kent M, Valenzuela R. Advanced Penile Length Restoration Techniques to Optimize Penile Prosthesis Placement Outcomes. Sex Med Rev 2020. [Epub ahead of print]. doi:10.1016/j.sxmr.2020.05.007.

34. Shaeer O, Shaeer K, el-Sebaie A. Minimizing the losses in penile lengthening: " $\mathrm{V}-\mathrm{Y}$ half-skin half-fat advancement flap" and "T-closure" combined with severing the suspensory ligament. J Sex Med 2006;3:155-60.

35. Borges F, Hakim L, Kline C. Surgical technique to maintain penile length after insertion of an inflatable penile prosthesis via infrapubic approach. J Sex Med 2006;3:550-3.

36. Hehemann MC, Towe M, Huynh LM, et al. Penile Girth Enlargement Strategies: What's the Evidence? Sex Med Rev 2019;7:535-47.

37. Nowroozi MR, Amini E, Ayati M, et al. Applying extender devices in patients with penile dysmorphophobia: assessment of tolerability, efficacy, and impact on erectile function. J Sex Med 2015;12:1242-7.

38. Kang DH, Chung JH, Kim YJ, et al. Efficacy and safety of penile girth enhancement by autologous fat injection

Cite this article as: Khalil MI, Machado B, Miranda A, Eltahawy E. Penile shortening complaints in males with erectile dysfunction: a narrative review on penile lengthening procedures during penile prosthesis surgery. Transl Androl Urol 2021;10(6):2658-2668. doi: 10.21037/tau-21-27 for patients with thin penises. Aesthetic Plast Surg 2012;36:813-8.

39. Silberstein J, Downs T, Goldstein I. Penile injection with silicone: case report and review of the literature. J Sex Med 2008;5:2231-7.

40. Casavantes L, Lemperle G, Morales P. Penile Girth Enhancement With Polymethylmethacrylate-Based Soft Tissue Fillers. J Sex Med 2016;13:1414-22.

41. Spyropoulos E, Christoforidis C, Borousas D, et al. Augmentation phalloplasty surgery for penile dysmorphophobia in young adults: considerations regarding patient selection, outcome evaluation and techniques applied. Eur Urol 2005;48:121-7; discussion 127-8.

42. Alei G, Letizia P, Ricottilli F, et al. Original technique for penile girth augmentation through porcine dermal acellular grafts: results in a 69-patient series. J Sex Med 2012;9:1945-53.

43. Austoni E, Guarneri A, Cazzaniga A. A new technique for augmentation phalloplasty: albugineal surgery with bilateral saphenous grafts--three years of experience. Eur Urol 2002;42:245-53; discussion 252-3.

44. Taylor FL, Levine LA. Surgical correction of Peyronie's disease via tunica albuginea plication or partial plaque excision with pericardial graft: long-term follow up. J Sex Med 2008;5:2221-8; discussion 2229-30.

45. Veale D, Miles S, Read J, et al. Penile Dysmorphic Disorder: Development of a Screening Scale. Arch Sex Behav 2015;44:2311-21.

46. Eid JF, Wilson SK, Cleves M, et al. Coated implants and "no touch" surgical technique decreases risk of infection in inflatable penile prosthesis implantation to $0.46 \%$. Urology 2012;79:1310-5. 